\title{
Quantitative discrimination of the nano-pore-structure of cement paste during drying: New insights from water sorption isotherms
}

\author{
Hamlin M. Jennings a ${ }^{\text {, Aditya Kumar }}{ }^{\mathrm{b}}$, Gaurav Sant ${ }^{\mathrm{b}, \mathrm{c}, *}$ \\ a Department of Civil and Environmental Engineering, Massachusetts Institute of Technology, Cambridge, MA, USA \\ ${ }^{\mathrm{b}}$ Laboratory for the Chemistry of Construction Materials $\left(L C^{2}\right)$, Department of Civil and Environmental Engineering, University of California, Los Angeles, CA, USA \\ c California Nanosystems Institute (CNSI), University of California, Los Angeles, CA, USA
}

\section{A R T I C L E I N F O}

\section{Article history:}

Received 26 November 2014

Accepted 5 May 2015

Available online 23 May 2015

\section{Keywords:}

Calcium-silicate-hydrate [C-S-H] (B)

Drying (A)

Adsorption (C)

Cement Paste (D)

Drying (A)

\begin{abstract}
A B S T R A C T
A new ability to quantitatively evaluate the complex pore system of cement pastes, using water sorption isotherms, is used to illuminate: (a) evolutions of microstructure during drying, (b) the mechanisms that control drying shrinkage, and (c) a novel method to compute the original w/c (i.e., water-to-cement ratio, mass basis). Each of these points has significant implications on concrete performance and durability in engineering practice. We show that irreversible changes in the nanostructure during first drying are associated with changes in the pores that empty between $\approx 85$-and- $45 \%$ relative humidity $(\mathrm{RH})$. It is also shown that water in the interlayer space (e.g., similar to clays) of the binding calcium-silicate-hydrate ( $\mathrm{C}-\mathrm{S}-\mathrm{H})$ phase, does not empty until drying below $\approx 25 \% \mathrm{RH}$. However, this water, once removed, does not completely re-saturate the pore spaces even at nearly $100 \%$ RH - for time scales on the order of weeks. With the ability to specifically identify the volume of pores associated with the $\mathrm{C}-\mathrm{S}-\mathrm{H}$ gel, as opposed to the larger capillary pores and the smaller interlayer spaces, a method for computing the original $\mathrm{w} / \mathrm{c}$ (and hence cement content), of cementitious material is proposed. These results suggest improved methods for evaluating and modeling the engineering behavior of cement-based materials.
\end{abstract}

(c) 2015 Elsevier Ltd. All rights reserved.

\section{Background and overview on water sorption isotherms}

It has long been suspected that water sorption isotherms, which probe the pore structure of cement paste at all scales where evaporable water resides, should be a very powerful tool for evaluating microstructure. Research on this topic has been active for decades [1-8], with special attention being paid to: (1) determining the specific surface area of the C-S-H [9-11] and (2) establishing relationships between the hysteresis (i.e., path dependence) that separates the adsorption and desorption curves and pore structure [12-16]. The various interpretations have been summarized in several papers $[17,18]$, but only recently has progress been made to interpret the full desorption/ adsorption isotherms. Recently, Pinson et al. [19] have advanced a new model that explains the role of the network structure on sorption hysteresis in porous media [20]. Pinson et al. divided pores into two categories so that a single conceptual picture explains the entire water sorption isotherm and its hysteresis [19]. Furthermore, the pore size distribution and other parameters are accessed, and used directly to model pore-network structure.

\footnotetext{
* Corresponding author at: Laboratory for the Chemistry of Construction Materials $\left(\mathrm{LC}^{2}\right)$, Department of Civil and Environmental Engineering, University of California, Los Angeles, CA, USA.

E-mail addresses: hmj@mit.edu (H.M. Jennings), adityaku@ucla.edu (A. Kumar), gsant@ucla.edu (G. Sant).
}

Since the work of Powers, Feldman and Sereda, and Roper, the mechanisms of drying shrinkage, have been a subject of discussion [21-26]. Helmuth and Roper provided evidence for assigning specific relative humidity ranges, as regions in which specific shrinkage mechanisms operate $[25,26]$. However, in their work, the mechanisms responsible for irreversible shrinkage were not resolved. Furthermore, a consistent issue has been that the low-pressure hysteresis (observed in sorption isotherms) is not similar to that observed in other porous materials, e.g., Vycor glass [27], although this feature is similar to other materials such as clays [28]. Explanations of this behavior have been varied and largely qualitative, and generally have not been translated into clear mathematical models useful for interpreting pore structure, moisture loss, drying and engineering properties. However, there has been less discussion on mechanisms of irreversible shrinkage (i.e., shrinkage that is not recovered upon resaturation), which, by general agreement, must involve some rearrangement or restructuring of the nano-scale $\mathrm{C}-\mathrm{S}-\mathrm{H}^{1}$ structure [29]. These volume changes, which

\footnotetext{
${ }^{1}$ Unless noted otherwise, standard cement chemistry notation is used. As per this notation, $\mathrm{C}=\mathrm{CaO}, \mathrm{S}=\mathrm{SiO}_{2}, \mathrm{H}=\mathrm{H}_{2} \mathrm{O}, \mathrm{A}=\mathrm{Al}_{2} \mathrm{O}_{3}, \mathrm{~F}=\mathrm{Fe}_{2} \mathrm{O}_{3}$. The $\mathrm{C}-\mathrm{S}-\mathrm{H}$ phase noted in cementitious systems has variable composition, and exhibits poor long-range order. In the case of alite, and OPC systems cured at ambient temperature and pressure, the $\mathrm{C}-\mathrm{S}-\mathrm{H}$ that forms shows a nominal composition around: $1.7 \mathrm{CaO}-\mathrm{SiO}_{2}-4 \mathrm{H}_{2} \mathrm{O}\left(\mathrm{C}_{1.7} \mathrm{SH}_{4}\right)$ though a wide-range of compositions are possible. This $\mathrm{C}-\mathrm{S}-\mathrm{H}$ shows two compositionally analogous but physically distinct forms, i.e., having a low density (LD) or high density (HD), which show differing densities due to distinct atomic packings.
} 
yet remain unclear, are of central importance to formation of large and small cracks, associated issues with concrete durability and, in particular, irreversible shrinkage.

It is clear that explicit understanding of the capillary, gel, and interlayer water (i.e., pore spaces) would improve our ability to characterize cement-based materials. Towards this end, we propose and demonstrate that water isotherms can be used to identify explicitly, the quantity of water contained within, and removed from the gel and capillary pores. Such information can be used to study relationships between microstructure and properties in cementitious materials.

\section{A brief discussion of the pore system in cement pastes}

\subsection{A. Interlayer spaces, with width available to water $\leq 2 \mathrm{~nm}$}

The characterizing feature for this type of space is its capacity to maintain water in the confined state down to low RH, e.g., $\leq 25 \% \mathrm{RH}$. Recent findings from molecular simulations and ${ }^{1} \mathrm{H}$ NMR estimate desorption from such nanopores to start between 20\%-and-25\% $\mathrm{RH}$ $[30,31]$. Traditionally the interlayer water is that defined as residing within and integral to the $\mathrm{C}-\mathrm{S}-\mathrm{H}$ layers (i.e., sheets), and includes water which exists in both tightly physisorbed, and chemisorbed states. We extend this definition to include contact regions where surfaces with different atomic orientations come into close proximity, and in certain cases, bond covalently. The removal of water from the interlayer spaces causes partial collapse of the solid, and therefore we prefer the term "space" over "pore" for this category. The behavior of water in these very small spaces is determined by intermolecular forces, and by the strong confinement produced by the interactions with sorbed, or solvated ions and other atoms. Because of the collapse and swelling of the solid-surfaces, i.e., walls of the confining regions, this water is associated with disjoining pressure, i.e., also referred to as hydration pressure. However, this term must be considered carefully as the physical pressure may not be maximum when the sheets are at their equilibrium saturated distance [32]. It is important to note that the interlayer space also includes water between the different particle-like regions, wherein granular structures (i.e., "globules" [33]) of different orientations may contact through adsorbed water.

\section{2. $B$. Gel pores, with widths between approximately $\approx 2$ and $\approx 8 \mathrm{~nm}$}

These pores are defined as the minimum porosity that can be achieved in a cement paste, i.e., the residual porosity that remains when the capillary pores are filled-in; when reaction products just-fill the original water-filled space [7,34]. The lower limit of $\approx 2 \mathrm{~nm}$ for this size class of pores corresponds to the upper limit of the interlayer space described above.

\subsection{Capillary pores, with width between $\approx 8 \mathrm{~nm}$ and $\approx 10 \mu \mathrm{m}$}

These pores are systematically diminished to zero as the w/c of different samples approaches 0.36 , i.e., wherein for a system cured at ambient temperature, the volume of reaction products formed, plus cement particles equals the total volume. When $\mathrm{w} / \mathrm{c}<0.36$, hydration is incomplete due to both space and water deficiency [66]. It should be noted that this condition of the elimination of the capillary porosity can be violated. For example: when cementitious materials are cured at elevated temperatures, the $\mathrm{C}-\mathrm{S}-\mathrm{H}$ densifies. The densification (i.e., the compaction due to the expulsion of water) of the $\mathrm{C}-\mathrm{S}-\mathrm{H}$ leads to the formation of expanded capillary pore spaces, due to coarsening of the microstructure [35]. On the other hand, when the w/c is exceedingly low, e.g., $w / c=0.23[36,37]$, the system hydrates only partially, and even available water is often not all consumed. This is because the systematic reduction in internal RH (and water activity) suppresses the continuation of hydration. This results in the existence of capillary

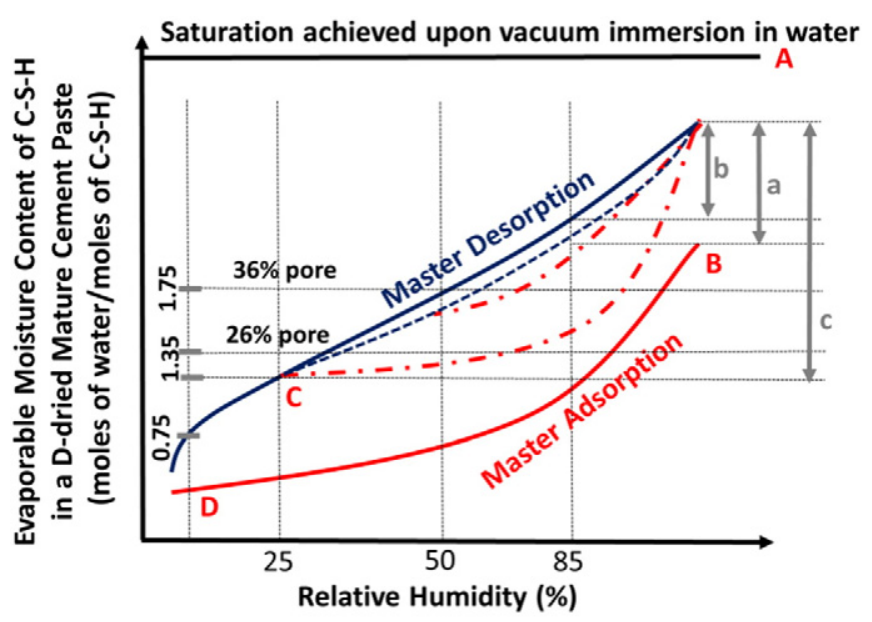

$a=$ decrease in gel pores on drying to $0 \% \mathrm{RH}$
\[ \begin{array}{c}\mathrm{b}=\text { capillary before drying } \\ \mathrm{c}=\text { gel pore before drying }\end{array} \]

Dashed lines show $2^{\text {nd }}$ desorption or adsorption following drying to $\mathrm{RH} \geq 25 \%, 50 \%$

Fig. 1. A composite sorption diagram for a mature cement paste of typical w/c as used in engineering practice. The diagram is illustrative only, and hence is not drawn to scale.

pores wherein unreacted water may reside, due to the incompleteness of hydration.

The capillary pores are responsible for the drying/rewetting hysteresis that occurs above $\approx 85 \% \mathrm{RH}$. Data from Roper and ${ }^{1} \mathrm{H}$ NMR has shown that $85 \% \mathrm{RH}$ is a relevant threshold to define capillary pores, and Kelvin's equation provides the corresponding pore width of $\approx 8 \mathrm{~nm}[23,31]$. Kelvin's equation also indicates that pores with a radius greater than $200 \mathrm{~nm}$ can fill only at $\mathrm{RH} \approx 100 \%$, i.e., under equilibrium conditions. As complete pore filling at $100 \% \mathrm{RH}$ is slow, except under water soaking, immersion or vacuum saturation conditions, pores larger than $200 \mathrm{~nm}$ can be considered devoid of any condensed water and simply lined with a thin layer of adsorbed water. We acknowledge the ongoing debate regarding whether small capillary pores with widths between 8 -and- $100 \mathrm{~nm}$ are intrinsic to the $\mathrm{C}-\mathrm{S}-\mathrm{H}$ or if they are leftover spaces from incomplete filling during chemical reactions $[1,31]$. This will be discussed in more detail later. Observations that water in the $\mathrm{C}-\mathrm{S}-\mathrm{H}$ is not removed until the $\mathrm{RH} \leq 25 \%$, allows the broader pore structure to be separated from the interlayer water for the purpose of analysis $[19,26,31]$. However, we will also show that a portion of the gel pores, which empties, leaving behind surface water, has an extremely small size, about $2 \mathrm{~nm}$ (in diameter), and which can practically, be grouped with interlayer water. From the data that follows, we propose a composite sorption diagram, shown in Fig. 1 that can be constructed to permit visualization of separate experiments, and sorption pathways. This diagram, and its experimental verifications are shown in the sections that follow.

A few points, drawn from the literature, must be made in order to interpret this diagram. First, there are two reference states, saturation and dry, i.e., essentially devoid of evaporable water. Each of these states has experimental challenges, such as keeping the sample wet with the largest pores full prior to starting measurements, and defining a dry state reliably $[7,38,39]$. While analysis of the literature suggests, based on scanning isotherms $[18,40,41]$, that an envelope for desorption and adsorption isotherms between 0 -and-100\% RH exists, we will for the first time confirm this explicitly. It should be noted that a number of water sorption isotherms have been acquired, for one $\mathrm{w} / \mathrm{c}$, to construct Fig. 1, which will be referred to throughout this paper.

As such, as the main objective, this paper will establish water sorption isotherms as a diagnostic tool to quantitatively evaluate the pore structure of cement based materials. We illustrate its use with 
Table 1

A summary of the classes of pores that exist in cement paste in terms of their operative differences. More details, and explanations of acronyms are noted in Section 4.

\begin{tabular}{|c|c|c|}
\hline $\begin{array}{l}\text { Relative humidity } \\
\text { (RH, \%) }\end{array}$ & $\begin{array}{l}\text { Desorption: Each experimental point of a desorption isotherm } \\
\text { represents a metastable equilibrium, where pores that should } \\
\text { be empty at a particular RH remain full due to a small entrance } \\
\text { to the pore that prevents a liquid vapor interface from entering. }\end{array}$ & Comments \\
\hline $100-$ to-85 & Capillary pores empty by a pore blocking mechanism. & The state of water is described by the Kelvin-Laplace \\
\hline $85-$ to-50 & LD-Gel pores empty by pore blocking. & equations, and the model of Pinson et al. [19]. \\
\hline $50-$ to-25 & HD-Gel pores continue to empty by pore blocking. & \\
\hline \multirow[t]{2}{*}{25 -to-0 } & $\begin{array}{l}\text { Interlayer water is removed. As this water is removed } \\
\text { the } \mathrm{C}-\mathrm{S}-\mathrm{H} \text { layers come together. }\end{array}$ & $\begin{array}{l}\text { The state of confined water can be modeled by molecular } \\
\text { dynamics, and measured by }{ }^{1} \mathrm{H} \text { NMR }[30,31] \text {. }\end{array}$ \\
\hline & $\begin{array}{l}\text { Adsorption: Each data point of the adsorption isotherm } \\
\text { represents near equilibrium states, depending on } \\
\text { the time scale of experiments. }\end{array}$ & \\
\hline 0-to-100 & Interlayer water saturates the interlayer spaces progressively. & $\begin{array}{l}\text { The near linear re-entry of water into these spaces is } \\
\text { accompanied by the development of disjoining pressures and forces. }\end{array}$ \\
\hline 0 -to-50 & Surface water is present in all pores, and filling of small gel pores occurs. & Governed by Langmuir/BET type physisorption. \\
\hline 50 -to-85 & Large gel pores fill in with liquid water. & The state of water is described by the Kelvin-Laplace equations. \\
\hline 85 -to-100 & Capillary pores fill in with liquid water. & \\
\hline
\end{tabular}

two examples: (1) to evaluate changes that occur on first drying that can be correlated with volume change (e.g., drying shrinkage), and (2) to forensically extract the original $\mathrm{w} / \mathrm{c}$ for a given cement paste (i.e., a mixture of cement, and water).

\section{Materials and experimental methods}

Sorption isotherms were acquired for well-hydrated pastes constituted using a Type I/II OPC and alite ( $\left.\mathrm{MIII}-\mathrm{Ca}_{3} \mathrm{SiO}_{5}[44]\right)$, aged greater than 6 months. Pastes were prepared by hand-mixing the powders with de-ionized water, at several water-to-solid ratios (by mass, w/ $\mathrm{s}=0.450,0.500$ and 0.650$)$. After mixing, the fresh pastes were sealed in airtight polyethylene containers (volume of $\approx 20 \mathrm{~cm}^{3}$ ) at $23 \pm 2{ }^{\circ} \mathrm{C}$. At the time of testing, the hardened pastes were ground and sieved through a $75 \mu \mathrm{m}$ sieve after which the powder samples were used for: (a) acquiring dynamic water vapor sorption (DVS) isotherms and (b) thermogravimetric (TGA/DTG) analysis to assess the degree of reaction of the cement pastes, and assess if carbonation may have occurred over the course of the DVS experiment.

The Type I/II OPC used had a composition of $59.2 \% \mathrm{Ca}_{3} \mathrm{SiO}_{5}, 16.7 \%$ $\mathrm{Ca}_{2} \mathrm{SiO}_{4}, 3.2 \% \mathrm{Ca}_{3} \mathrm{Al}_{2} \mathrm{O}_{6}, 10.3 \% \mathrm{Ca}_{4} \mathrm{Al}_{2} \mathrm{Fe}_{2} \mathrm{O}_{10}, 2.2 \% \mathrm{MgO}, 0.6 \% \mathrm{CaSO}_{4}$, $2.6 \% \mathrm{CaSO}_{4} \cdot 0.5 \mathrm{H}_{2} \mathrm{O}, 1.0 \% \mathrm{CaSO}_{4} \cdot 2 \mathrm{H}_{2} \mathrm{O}, 3.4 \% \mathrm{CaCO}_{3}, 0.6 \%(\mathrm{Ca}, \mathrm{Mg})\left(\mathrm{CO}_{3}\right)_{2}$ and $0.5 \% \mathrm{~K}_{2} \mathrm{SO}_{4}$ as determined using quantitative $\mathrm{x}$-ray diffraction (QXRD). The specific surface area (SSA) of the OPC was $486 \mathrm{~m}^{2} / \mathrm{kg}$ as determined using its measured particle size distribution (using static light scattering) and assuming spherical particles. This assumption underestimates the specific surface area by a factor ranging between 1.0-and-1.8 [42] though this can magnify further depending on the roughness of solid surfaces.

Dynamic water vapor sorption isotherms were acquired using a custom-built instrument. The analyzer measures the uptake/loss of water from a sample, gravimetrically, using a microbalance with a mass resolution of $\pm 1 \mu \mathrm{g}$ allowing assessments of the adsorption and desorption of minute quantities of a probe molecule, in this case water vapor. The microbalance used has a dynamic range of $1.5 \mathrm{~g}$ and a maximum lift capacity of $4.5 \mathrm{~g}$. The vapor pressure of water in contact with the solid sample is controlled by mixing saturated/dry carrier gas streams using electronic mass flow controllers. $\mathrm{N}_{2}$ ( $>99 \%$ purity) was used as a carrier gas to prevent any carbonation of the samples. This was confirmed by pre-and-post experiment analysis of $\mathrm{CaCO}_{3}$ contents of powders subject to sorption determinations, using thermal analysis (TGA/DTG). The temperature of the overall system which is enclosed within a thermostated incubator is within $24 \pm 0.2{ }^{\circ} \mathrm{C}$ over the course of the experiments.

In a typical experiment, a quantity of cementitious powder (between 50 -and-100 $\mathrm{mg}$ ) is placed in a sample pan and compacted by tamping. The sample pan is then placed in the DVS analyzer at a desired temperature (in this case, $\approx 24^{\circ} \mathrm{C}$ ) and equilibrated at $98 \%$ RH. As an example: mass was first sampled at $98 \% \mathrm{RH}$, followed by step-by-step sampling from $90 \%$-to- $0.7 \% \mathrm{RH}$ in $10 \% \mathrm{RH}$ increments. Adsorption isotherms were acquired by reversing the RH steps sampled. Because we are exploring the use of sorption isotherms to analyze structure at different scales the minimum RH sampled was varied between $0.7 \%$ $\mathrm{RH}, 25 \% \mathrm{RH}$ and $50 \% \mathrm{RH}$. This provides information about which pore spaces undergo irreversible changes. It should be noted that the DVS instrument used in this study is unable to achieve true dry or wet states, i.e., $\mathrm{RH}=0 \%$ and $\mathrm{RH}=100 \%$ respectively. Rather on account of instrumental limitations, the range of experiments carried out herein span dry, and wet states established at $\mathrm{RH}=0.7 \%$ and $\mathrm{RH}=98$-to-99\% respectively. These states ensure a finite driving force (i.e., difference in chemical potential) which allows drying, or wetting to occur [43]. Multiple sorption cycles were obtained to confirm that no further changes are observed after the first drying. At each $\mathrm{RH}$, mass equilibrium was attained when the percent mass change per unit time $(\mathrm{dm} / \mathrm{dt})$ was less than $0.001 \% / \mathrm{min}$, or when the residence time at a given RH step exceeded 1440 min; which ever occurred earlier. This $\mathrm{dm} / \mathrm{dt}$ value was chosen based on prior studies [44]. Once the mass change criterion, and thus metastable or equilibrium conditions were achieved the experiment proceeded to the next programmed RH step. Data acquisition was carried out at 20 -second intervals for the duration of the experiment.

Thermogravimetric (TGA/DTG/DTA) analysis was carried out on powdered paste samples using a simultaneous thermal analyzer manufactured by Perkin Elmer (Model: STA 6000). The powder samples were heated under UHP-N ${ }_{2}$ (99.999\% purity) purge at a flow rate of $20 \mathrm{ml} / \mathrm{min}$ and at a heating rate of $10^{\circ} \mathrm{C} / \mathrm{min}$ in pure aluminum oxide crucibles over a temperature range from $35^{\circ} \mathrm{C}$ to $975{ }^{\circ} \mathrm{C}$. The weight loss (TGA) and differential weight loss (DTG) patterns acquired were used to identify the degree of reaction of the cement pastes. The extent of cement reacted, that is, its degree of reaction (as a fraction), is quantified via the non-evaporable water content, commonly characterized as the mass loss between $145{ }^{\circ} \mathrm{C}$-and$975^{\circ} \mathrm{C}$, discounting the mass loss, if any, that is associated with the decomposition of $\mathrm{CaCO}_{3}$ and the loss on ignition ( $\mathrm{LoI}, \mathrm{g} / \mathrm{g}_{\text {cement }}$ ) of the raw cement powder [66].

\section{Results and discussion: the water sorption isotherm: evaluation of pore structure and changes in pore structure on first and subsequent drying}

An important point included in Table 1 is that no water leaves the interlayer spaces during desorption until approximately $\mathrm{RH} \leq 25 \%$ is achieved. Therefore, for $\mathrm{RH} \geq 25 \%$, the $\mathrm{C}-\mathrm{S}-\mathrm{H}$ phase (when separated from the capillary pores) can be considered as a "solid" of constant 


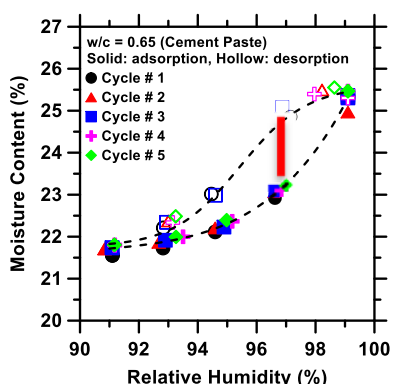

(a)

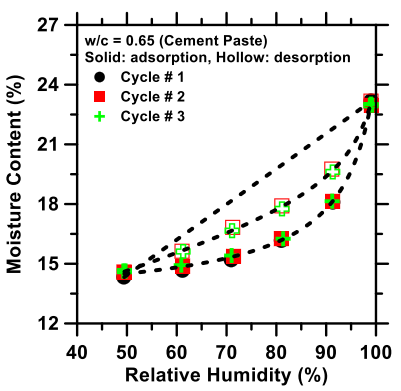

(b)

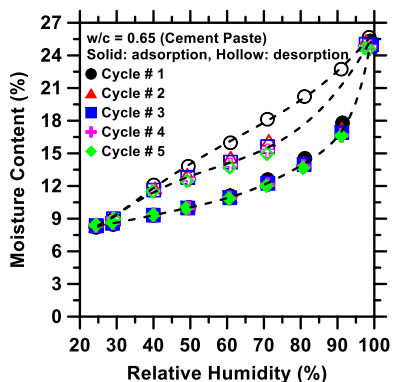

(c)

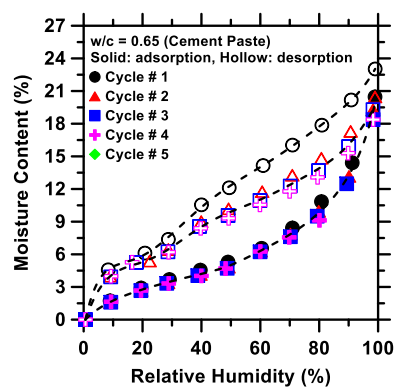

(d)

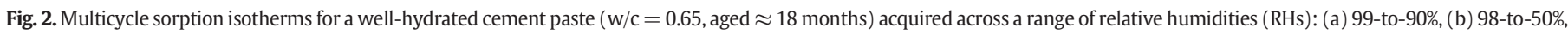

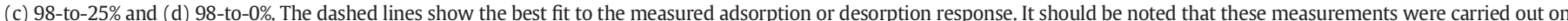

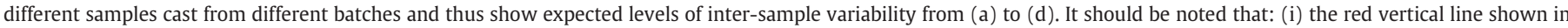

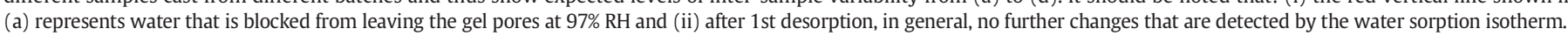

composition and properties. It is at this time clear that the primary reason for the high-pressure hysteresis in cementitious sorption isotherms is pore blocking [19]. This mechanism is operative for $\mathrm{RH} \geq 25 \%$. Pore blocking is the consequence of a series of pores that are connected to the ambient, but having narrow necks, such that the larger pore interiors cannot empty until a $\mathrm{RH}$ where the liquid-vapor interface can pass through the neck - i.e., the so-called ink-bottle effect. A pore network of this nature invokes regions of "solid" with near neighbor regions in contact, and while this picture might invoke a granular structure, the bonds between regions could be as strong as the bonds between layers of $\mathrm{C}-\mathrm{S}-\mathrm{H}$ [45]. A visual illustration of a cementitious microstructure is provided in Fig. 3, and in Fig. 6.

This section explores the pore structure, and changes in pores between first and second drying, to each of four specific relative humidities, followed by near resaturation. The data for these drying cycles are plotted in Fig. 2. As is seen, all of the changes, if they occur, occur during the first drying cycle, with subsequent drying cycles imposing no detectible further changes. In spite of the drying process starting at near saturation $(\approx 98 \%)$, we frame our discussion in terms that use the moisture content around $0 \% \mathrm{RH}$ (i.e., $\approx 0.7 \% \mathrm{RH}$, to be precise) as the reference state, due to the different saturation moisture contents that can be achieved, e.g., as a function of w/c, the time interval, and the procedures applied for ensuring moisture saturation. It should be noted that while this study imposes limits on RH such that, $0.7 \% \leq \mathrm{RH} \leq 98 \%$, small differences in the RH limits, especially at the low end of the RH spectrum may induce substantial differences in the shape of the isotherms, and the hysteresis between the drying and wetting curves, as shown by Feldmann and Sereda [18] who highlighted such effects when the minimum $\mathrm{RH}$ achieved was decreased from $\mathrm{RH}=2 \%$ to $\mathrm{RH} \approx 0 \%$.

\subsection{Capillary pores ( $99 \% \leq R H \leq 85 \%)$}

Fig. 2(a) shows an isotherm of a sample dried to $91 \% \mathrm{RH}$, which is well-within the estimated bounds for the capillary pores. These pores are connected to the ambient by passages down to about $50 \mathrm{~nm}$ in diameter. As shown for the first time, and will be discussed in detail, there is a significant hysteresis. At any RH the difference between the desorption and adsorption branches is the amount of water trapped behind smaller passages to the ambient (pores). The solid red line in Fig. 2(a) represents this value for a $\mathrm{RH}=97 \%$, though it is noted that by $\mathrm{RH}=90 \%$, the sorption-desorption curves begin to merge towards a horizontal asymptote. Significantly, the shape of the desorption curve, approaching a horizontal slope with almost no hysteresis, suggests that pores or pores with entrances in the size range of about $20 \mathrm{~nm}$ in diameter are emptied of water by $90 \% \mathrm{RH}$. This horizontal asymptote achieved at high RH shows a clear means of discriminating capillary pores, from the remainder of the pore structure. In other words, since no pores are emptying over this range, i.e., around
$\mathrm{RH} \approx 90 \%$, and we know that smaller pores will empty only at lower RH's, there is a gap in pore sizes that serves as a means to quantitatively define capillary pores. While it may be so that no further pores empty down to $85 \% \mathrm{RH}$, a value identified by Roper [23], further work is needed to validate this point. Over the range of RHs considered, $99 \% \leq \mathrm{RH} \leq 90 \%$, all successive adsorption and desorption curves overlay each other. This suggests that no irreversible microstructural changes occur up on drying to around $90 \% \mathrm{RH}$.

\subsection{Gel pores ( $85-25 \% R H)$}

Gel pores have been defined as the minimum porosity intrinsic to the $\mathrm{C}-\mathrm{S}-\mathrm{H}$ in cement paste. Here we assign gel pores as those that empty between $85 \% \leq \mathrm{RH} \leq 25 \%$. We divide this $\mathrm{RH}$ region into two pore categories: the large gel pores that empty up on drying to $\approx 50 \%$ $\mathrm{RH}(\approx 4 \mathrm{~nm}$ diameter) and the small gel pores that empty on further drying until $\approx 25 \% \mathrm{RH}(\approx 2 \mathrm{~nm}$ diameter $)$. It should be noted that this assignment is based on an inflection point around the $50 \% \mathrm{RH}$ range noted especially up on 2nd and subsequent drying cycles [23,29,41]. It has been previously noted that pores larger than $\approx 4 \mathrm{~nm}$ in diameter are a part of the LD (low density) C-S-H [46]. As shown in Fig. 2(c), significant structural change, shown by comparing first and second drying, occurs up on first drying within the range 85 -to-50\% $\mathrm{RH}$; corroborating our reasoning for the division of gel pores into two categories. We note that though the resolution of these isotherms does not include the horizontal asymptote that appears around $90 \% \mathrm{RH}$ this is the first time that capillary and gel pores are explicitly identified in direct correlation with the irreversible microstructural changes that occur upon drying (discussed later).

\subsubsection{Large gel pores ( $L G P, 85 \% \leq R H \leq 50 \%$ )}

By comparing the desorption isotherms (i.e., the 1 st to subsequent drying cycles, see Figs. 1 and 2b-d) above and below $85 \% \mathrm{RH}$, it is clear that when dried to $50 \% \mathrm{RH}$ the total pore volume emptied above $85 \% \mathrm{RH}$ increases substantially, while the pore volume emptied below $85 \%$ RH below decreases proportionally. The collapse of the LGP within this $\mathrm{RH}$ range must be associated with irreversible shrinkage, which typically shows a value around $3000 \mu \varepsilon$ in pure cement pastes [25]. Careful examination of Fig. 2(b) also shows nearly complete recovery of the pore volume upon adsorption at near saturation (i.e., $\approx 98 \%$ $\mathrm{RH})$. Thus, desorption likely induces rearrangements of the microstructure, e.g., see change in desorption path from Cycle \# 1 to Cycle \# 2 (Fig. 2b and c). The overall porosity (but not the external bulk volume) remains constant. However, even near resaturation conditions do not fill all of the pores. Only pores smaller than about $100 \mathrm{~nm}$ in diameter are filled, leaving the micron size capillary pores empty. While this does imply that the larger pores are not accessible by the water sorption method used herein, the discussion does support the idea that the LGP are associated with the LD C-S-H structure [41]. 


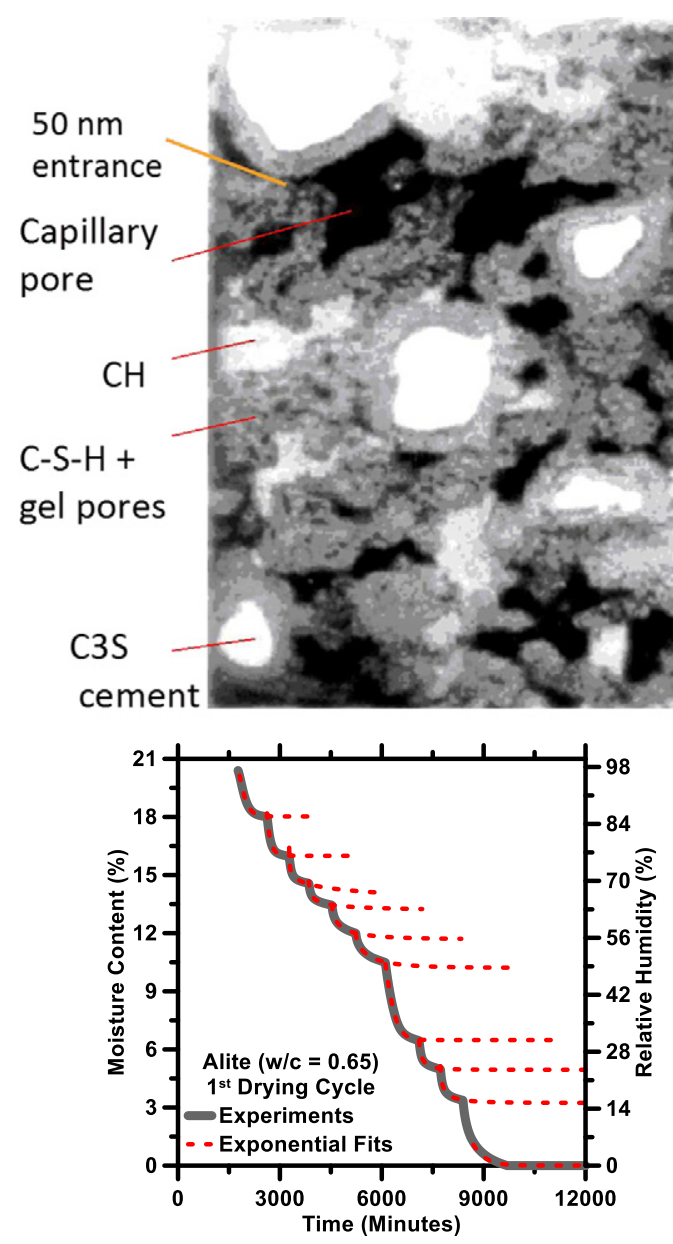

(b)

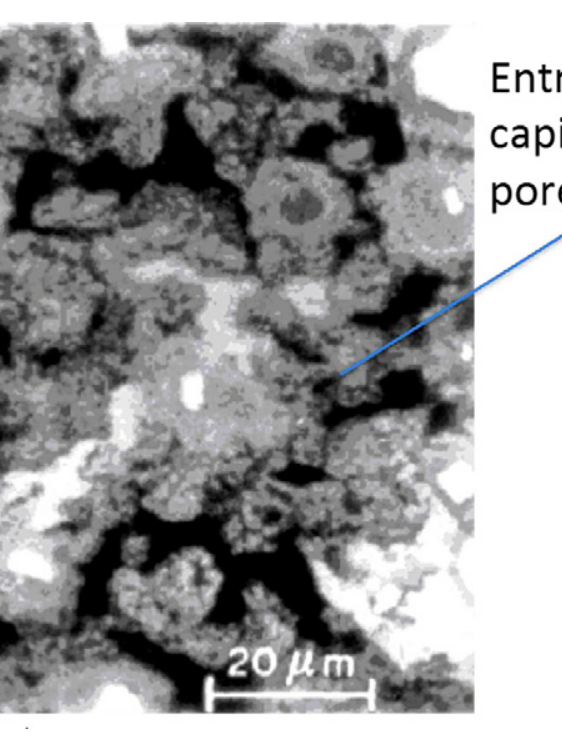

Entrapped capillary pore (a)

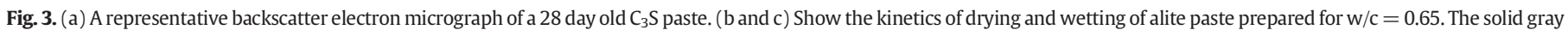

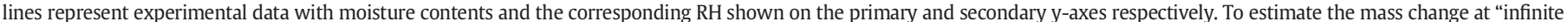
time" the experimental data were extrapolated using an exponential Weibull function to determine how close to equilibrium the measured isotherms may be.

\subsubsection{Small gel pores (SGP, $50 \% \leq R H \leq 25 \%$ )}

When drying to $25 \% \mathrm{RH}$ the changes in the desorption isotherm between first and second drying occur mostly for $\mathrm{RH} \geq 45 \%$ (Fig. 2c). This indicates that the SGP, or the pores associated with the HD C-S-H, experience little, if any change when emptied, i.e., they might be already compacted into the densest possible structure. Therefore, it appears as though the distinction between the smallest gel pores and the interlayer spaces is perhaps blurred?

\subsubsection{Interlayer space $(R H \leq 25 \%)$}

Drying below $25 \%$ RH induces substantial changes that separate $1^{\text {st }}$ from subsequent desorption cycles (see moisture content at $\mathrm{RH}=$ $98 \%$ in Figs. $2 \mathrm{~d}$ and 3a). The hysteresis becomes more pronounced which has been associated with the removal of interlayer water starting at $25 \% \mathrm{RH}$, but which can re-enter this space over the entire $\mathrm{RH}$ range depending on the time duration, and the RH offered for re-entry [45]. Also we note that the total volume of pores filled during resaturation does not fully recover herein; though it may be otherwise in the event vacuum saturation and/or water immersion were to be employed. ${ }^{2}$

\footnotetext{
${ }^{2}$ We have run other experiments, e.g., using phase pure C-S-H's (of different molar ratio), wherein wetting and drying steps up to 2-3 weeks long, at each step, have been permitted. Even over these long durations complete re-entry of water into the interlayer spaces has not been observed. As such, it is clear that at least over practical time scales, refilling of such spaces is unlikely to occur.
}

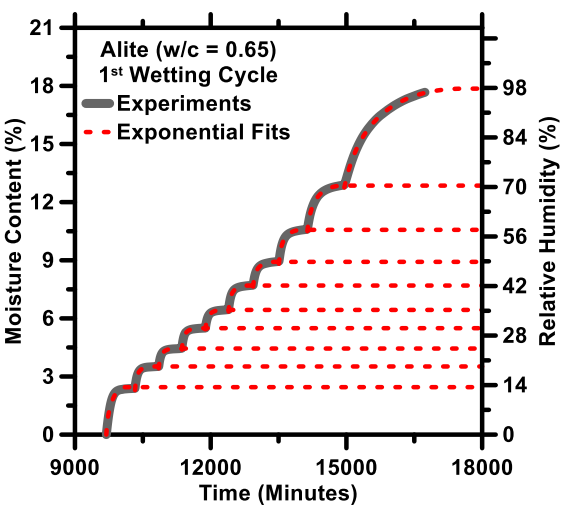

(c)
This effect, which is repeatable and has been noted for decades across numerous samples, $\mathrm{w} / \mathrm{c}$ etc., is associated with pore spaces that empty and do not refill within the interlayer space. Given the dimensions of the interlayer spaces and the chemical potential of water contained therein (as described by Kelvin's ${ }^{3}$ equation $[47,48]$ ), these are estimated to be the intraglobular pores (IGP) described in [31], a subset of the interlayer space.

The complete resaturation of the interlayer(s) is unlikely even at very long time scales, at least for the RH conditions (i.e., inferior to saturation) achieved in our experiments [49,50]. Regarding equilibrium, visualization of representative kinetic curves of wetting-and-drying of an alite paste shown in Fig. 3b-c highlight that in general "near equilibrium" is more readily achieved during wetting and drying for RH's $\leq 70 \%$. This is explained by the fact that transport is facilitated when pore pathways are unobstructed by liquid (bulk) water bridges. Significantly, it has been noted that, when enough water is removed and two adjacent interlayer surfaces contact, solid-solid bonds form,

\footnotetext{
${ }^{3}$ It is recognized that the distinction of capillary and gel pores as identified in the cement literature is arbitrary. For the case at hand, we recognize capillary pores as those in which a coherent liquid meniscus exists and the capillary stress is described by the Kelvin-Laplace equation. Gel pores are those in which a liquid meniscus is not expected to exist (i.e., they contain only adsorbed water) - nonetheless, the thermodynamic potential of water contained in such spaces, can be represented by the Kelvin equation as a function of the partial vapor pressure of water vapor contained therein.
} 


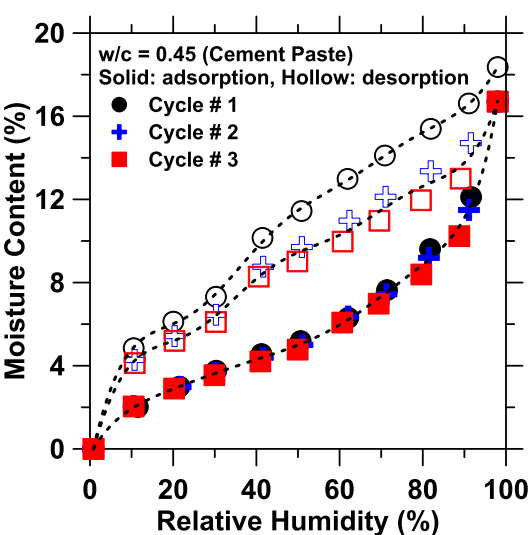

(a)

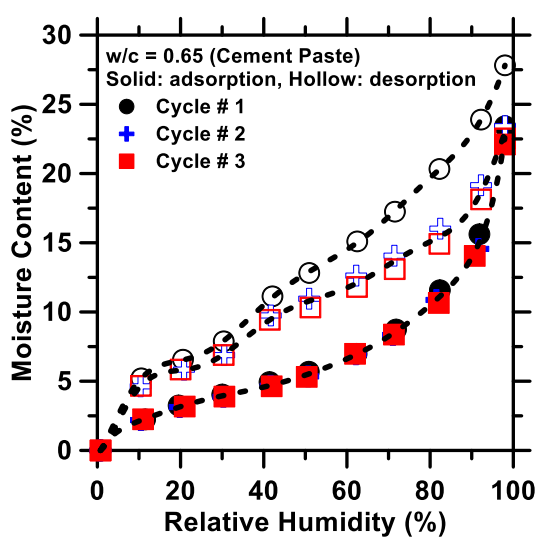

(b)

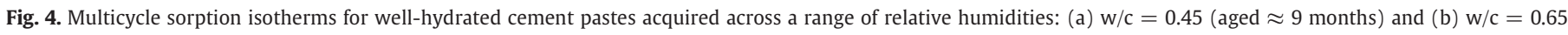
(aged $\approx 9$ months). The dashed lines show the best fit to the adsorption or desorption response.

which increases the degree of C-S-H polymerization and its density, which, in turn, reduces the porosity [45]. This explains the nature of irreversible bulk volume changes that are observed upon drying to $\approx 0 \%$ $\mathrm{RH}(\approx 0.7 \% \mathrm{RH}$ in this case), and more specifically, for RHs $\leq 25 \%$.

Shrinkage has been studied using an environmental scanning electron microscope (ESEM) and an image analysis algorithm that compares images to detect changes in the volume of a feature in the microstructure, pixel by pixel [51]. As seen in the image the capillary pores are much larger than the pore necks, and therefore they fill, during adsorption, by equilibrium thermodynamics (i.e., as described by the KelvinLaplace equation), of the internal space at much higher partial pressures than those that would fill pores with a size corresponding to the neck entryway. The results of an study conducted by Neubauer et al. show that the very large volume changes that are associated with emptying the interlayer spaces, and the reduction in the bulk volume, are in part compensated by fissure-like networks that form throughout the microstructure $[51,52]$. Thus the fundamental objection that emptying the interlayer space over estimates the bulk shrinkage can be tolerated because of the expansions caused throughout the microstructure due to fissure formation $[12,13]$. Chappuis [53] postulated that internal shrinkage is prevented due to the rigid structure of the cement paste; a rather compact entanglement of $\mathrm{C}-\mathrm{S}-\mathrm{H}$ and other crystals and highlighted that drying causes an increase in the sizes of capillary pores, in relation to severity of drying. This increase in the size of capillary pores causes local expansions, which allows for the compensation of shrinkage that occurs within the interlayer spaces. On a related note, Adolphs et al. [54] showed that if drying occurs for $\mathrm{RH}<50 \%$, the critical pore diameter (assessed by $\mathrm{Hg}$ intrusion) decreases, suggesting a collapse in the porosity. It should be noted however, that in addition to pore-size, changes in specific surface area and surface morphology would also affect shrinkage behavior during drying and wetting. For example, Völkl et al. [55] showed that the specific surface area of the exposed $\mathrm{C}-\mathrm{S}-\mathrm{H}$, as measured by small-angle X-ray scattering (SAXS), decreased by $35 \%$ in samples that were dried from saturation to $\mathrm{RH}<50 \%$. Similarly, changes in surface morphology and a large increase in specific surface area were detected via atomic force microscopy (AFM) investigations on hardened cement pastes as they were wet from a dry state, i.e., from $3 \% \mathrm{RH}$ to $20 \% \mathrm{RH}$ [56]. These collective observations highlight why the measured bulk shrinkage is smaller than expected: due to the effects of local expansions, and the internal and external volume compensations that counteract each other. Importantly, the sum of the fractions of internal (e.g., layer collapse) and external volume change, near perfectly, recover the observed shrinkage of the bulk sample. However, we note that extreme drying can cause further increased irreversible shrinkage, which may be important during fire or extreme events $[25,26]$.

\section{The influence of age on the volume of gel pores and their densification}

Careful examination of Figs. 4 and 5 shows that the difference between the first and subsequent desorption cycles becomes less pronounced with age. As a detailed example, for $\mathrm{w} / \mathrm{c}=0.65$, the volume of LD pores decreases with age up to 27 months. The gel, especially the LD C-S-H slowly compacts with age, an effect that is not accounted for by an increase of reaction, (i.e., an increase in stiffness with age and reaction time) [74,75], as has been widely reported in the cement literature. This is direct evidence that the LD-pores, slowly collapse, with the passage of time - explaining as an example why the C-S-H bulk density (i.e., including its gel water) increases with time [31]. This may explain the substantial increase in the degree of polymerization of the $\mathrm{C}-\mathrm{S}-\mathrm{H}$ phase that accompanies the pore collapse process [45,57].

It is interesting to note that the difference between 1st and 2nd desorption is vanishingly small when an older sample is dried to only $25 \% \mathrm{RH}$ (see Fig. 5b). However, when the sample is dried to $0.7 \% \mathrm{RH}$, there is a clear and measurable difference between the 1st and 2nd desorption in the region of $\mathrm{RH}$ associated with the gel pores (i.e., $85 \% \leq \mathrm{RH} \leq 25 \%$ ) - see Fig. 5(c). This indicates that, in addition to aging, the removal of interlayer water, compacts the pore structure by pulling neighboring solid surfaces together.

\section{Practical application: determining the $w / c$ of cement pastes using adsorption isotherms}

The water-to-cement ratio ( $\mathrm{w} / \mathrm{c}$, by mass) is central to engineering practice because it controls mechanical properties such as strength, and, importantly, the durability of concrete. Evaluating the original $\mathrm{w} / \mathrm{c}$ is important to quality control, design, and the evaluation of existing structures, including establishing compliance with specification. By definition, determination of $\mathrm{w} / \mathrm{c}$ requires information about the volume of space occupied by cement, reaction products, and remaining capillary pores. While several methods such as chemical extraction (BS1881:124:1988 [58]) and fluorescence microscopy (Nordisk NT361-1999 [59,60]) have been applied to w/c determination, e.g., in forensic evaluations, these techniques, apply significant assumptions to compute the original $\mathrm{w} / \mathrm{c}$, especially when aggregates are present. While, recently Wong and Buenfeld [61] have applied a novel backscatter electron imaging (BEI) method to estimate the original $\mathrm{w} / \mathrm{c}$, including the effects of aggregate, challenges with calibration and ease of use still remain a concern.

To overcome the limitations of the methods noted above, we propose and describe a new approach, and present an algorithm that provides an improved method for determination of the original w/c. 


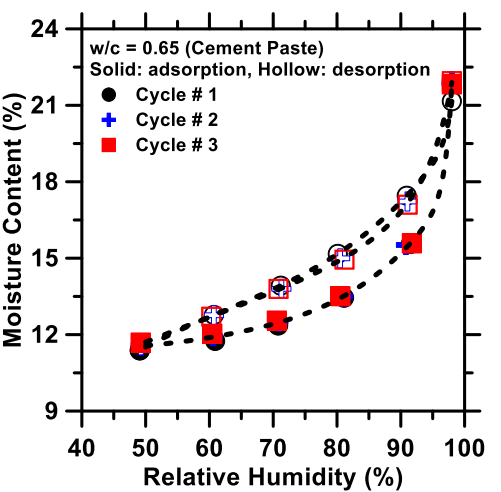

(a)

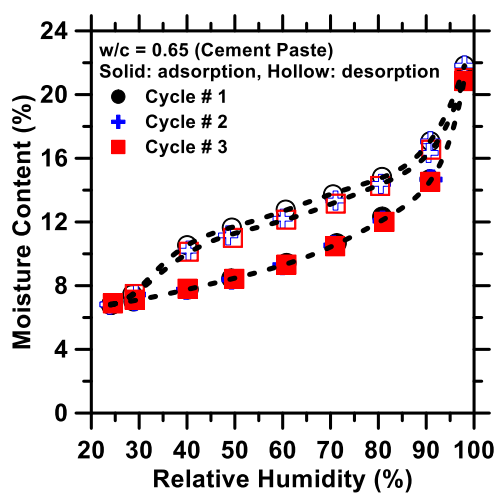

(b)

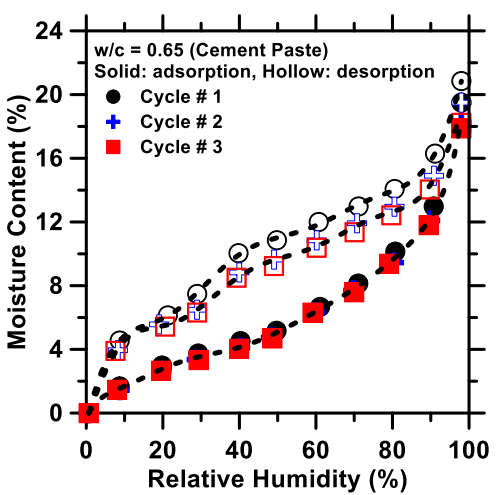

(c)

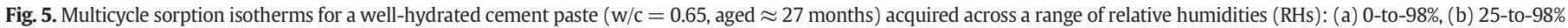

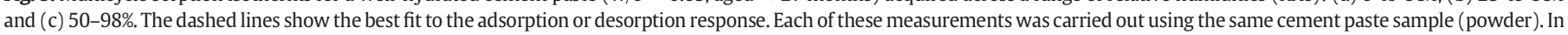
the case of desorption, the 2nd and subsequent cycles overlay each other, while in the case of adsorption, all cycles, for a given RH minimum, overlay each other.

At this time, we admit that our approach is a proof of concept, and further research and optimization of parameters is needed, but the advantages may be significant. Importantly, the proposed technique renders aggregates, air voids and other fillers such as fibers, or any inert minerals invisible, and hence renders them incapable of contaminating the $\mathrm{w} / \mathrm{c}$ determination.

Using the pore space interpretations described above the gel/capillary pore volumes are taken directly from the sorption isotherm. These parameters can be used to compute Powers' gel/space ratio $(\chi$, unitless: Eq. (1)), which, when inverted, is a robust measure of original w/c; as it has been tested and validated over several decades, in relation to cement composition and age. Since the gel/space ratio is only sensitive to the extent of cement reacted, determination of the reacted cement fraction, quantifies the gel/space as a function of $\mathrm{w} / \mathrm{c}$.

Some background of the gel/space ratio is required [7,62]. Powers originally defined capillary pores as those that generate capillary stresses $[7,63,64]$. He exhaustively tested cement pastes with different $\mathrm{w} / \mathrm{c}$ and showed that adsorption isotherms, clearly denoted the separation of capillary pores from the gel pores; wherein the volume of the former, increased with w/c [7]. Powers defined gel pores as those that fill at around four times the water content necessary to form a monolayer on the $(\mathrm{C}-\mathrm{S}-\mathrm{H})$ gel particles, typically defined as the quantity of water sorbed, during adsorption at $11 \% \mathrm{RH}$. This is the minimum volume of pores that must form within the gel, which occurs at $\mathrm{w} / \mathrm{c}=$ 0.36 - based on the premise of space constraints on hydration [66]. Using density and other physical data of the $\mathrm{C}-\mathrm{S}-\mathrm{H}$, Powers determined that gel pores occupy $\approx 26 \%$ of the total gel volume. Then, naturally, the capillary pores are spaces that reside outside of the gel. Powers admitted that the separation of gel and capillary pores was arbitrary because the larger gel pores could experience capillary condensation and pressures. In spite of its insightful nature, the main weakness of Powers original analysis is that he did not account for the role of interlayer water, which was grouped together with gel water [7].

On the other hand, Feldman and Sereda assigned most of the water to the interlayer spaces [22]. These highly opposing viewpoints, have frustrated the interpretation of water sorption isotherms for decades and have complicated the measurement of the gel space ratio. However, as noted herein, it is highlighted that interlayer water can be decoupled from gel water (see Fig. 2, and the discussion that follows). With this understanding, an algorithm can be formulated to quantify the gel and capillary pore volumes, and hence determine the $\mathrm{w} / \mathrm{c}$ of a cement-based material. The following numerical values are needed to enable such $\mathrm{w} / \mathrm{c}$ determinations:

(i) Saturated value where all pores are full: This is the maximum value noted upon the first drying (desorption) of a cementitious material (see Point A in Fig. 1). This is a difficult point to assess, because even a small extent of evaporation can easily empty large pores that penetrate the sample surface. We highlight that this point can be estimated (to the 1st order) by fitting high order polynomials to the 1st desorption isotherm, across the entire $\mathrm{RH}$ range, and then estimating the moisture content value at $100 \% \mathrm{RH}$. While it is understood that this method is imperfect (due to sharp increases in the moisture content in the overhygroscopic, i.e., $\mathrm{RH}>98 \%$ regime), as a first approximation, it is acceptable.

(ii) Point where gel pores are empty and interlayer space are saturated: This is the value achieved on first desorption when the gel pores are empty and the interlayer spaces are full at some $\mathrm{RH}$ ranging between 10-and-25\% RH (Point C in Fig. 1).

(iii) Point where the gel pores and interlayer spaces are saturated: Powers' gel/space ratio, defines the separation between gel/capillary pores as noted above. This idea is maintained herein. As such, Point B in Fig. 1, is defined as four times the value on the adsorption curve that represents monolayer coverage on the surface of the "globules" (see Point D in Fig. 1) [41]. The statistical monolayer from our data was determined at $\approx 22.5 \%$ RH for cement paste and $\approx 11 \% \mathrm{RH}$ for alite paste. This difference in the RH values corresponding to monolayer coverage for alite and cement pastes (i.e., Point D) is justified by noting that low-pressure hysteresis is far more pronounced for cement pastes rather than alite pastes [44]. The change in the RH corresponding to monolayer coverage is likely a function of: (i) geometrical differences in these microstructures, i.e., the topology of which is more complex in cement, than alite pastes, (ii) the presence of phases other than $\mathrm{C}-\mathrm{S}-\mathrm{H}$ and portlandite (e.g., AFm and AFt) in cement pastes, which contribute, albeit slightly, to the sorption isotherm and (iii) slight differences in the $\mathrm{C}-\mathrm{S}-\mathrm{H}$ in alite and cement pastes, e.g., in terms of $\mathrm{Ca} / \mathrm{Si}$ (molar ratio; around 1.7 for alite pastes and $1.8-2.0$ for cement pastes); an aspect which may alter partitioning of surface and interlayer water as a function of the $\mathrm{C}-\mathrm{S}-\mathrm{H}$ composition, and hence the RH at which monolayer coverage is recognized $[57,66]$. It should be noted that exact determination of statistical monolayer formation, and hence capacity from water vapor sorption on hydrophilic surfaces is complex as water molecules could sorb in patches, and occupy multilayer configurations on the exposed C-S-H surface. Therefore, the monolayer should be treated as statistical rather than exact.

\subsection{Gel pores}

The volume of gel pores $\left(\mathrm{V}_{\mathrm{GP}}\right)$ is obtained by subtracting (ii) from (iii), while the volume of capillary pores is obtained by subtracted (iii) 
Table 2

A comparison of the design and calculated $\mathrm{w} / \mathrm{c}$ of pastes constituted using alite and ordinary Portland cement (OPC), as reactants, and water. The uncertainty in the calculated degree of reaction is determined based on the analysis of 3 replicate samples.

\begin{tabular}{llll}
\hline Reactant & w/c (design) & Degree of reaction $(-)$ & w/c (calculated) \\
\hline Alite & 0.45 & $0.85 \pm 0.03$ & 0.44 \\
Alite & 0.65 & $0.85 \pm 0.03$ & 0.63 \\
OPC & 0.45 & $0.80 \pm 0.03$ & 0.48 \\
OPC & 0.65 & $0.80 \pm 0.03$ & 0.67 \\
\hline
\end{tabular}

from (i). Solution of the gel/space ratio equation requires quantities expressed as ratios, which can be determined from sorption isotherms. This uniquely renders air bubbles, aggregates and other fillers invisible to the determined value of the gel-space ratio ( $\chi$, unit less: Eq. (1)). Knowing that the cement gel contains $\approx 26 \%$ porosity $[65,66,7]$, the moisture content attributed to the gel pores can be used to estimate the quantity of gel including its porosity (i.e., hydration product, $\mathrm{V}_{\mathrm{G}}$ ). Similarly, the capillary porosity can be estimated from the adsorption isotherm as the moisture content between $85 \%$-and-100\% $\mathrm{RH}\left(\mathrm{V}_{\mathrm{CP}}\right)$ as discussed above. This data can be used in Eq. (1) to estimate the (original) w/c as follows:

\begin{tabular}{ll}
$x=\frac{V_{G}}{V_{G}+V_{C P}}=\frac{0.68 \alpha}{0.32 \alpha+w / c}$ & Eq. (1a) \\
$V_{G}=\frac{V_{G P}}{0.26}$ & Eq. (1b) \\
\hline
\end{tabular}

where: $V_{\mathrm{G}}$ is the volume of gel (including gel pores) in the system (fraction), $\alpha$ is the degree of reaction of the cement (fraction) and $w / c$ is the water-to-cement ratio (mass basis, unitless). In Eq. (1), when the degree of OPC reaction is known (which ranges between $0.80<\alpha<0.85$ for the pastes considered here), and $\chi$ is computed, the only unknown that remains is the $\mathrm{w} / \mathrm{c}$ of the cement (or the alite) paste. As noted in Table 2, there is an excellent agreement between design and calculated values of $\mathrm{w} / \mathrm{c}$, though additional data would serve to further strengthen and further validate the proposed approach. Knowledge of the gel/space ratio, and in turn, the $\mathrm{w} / \mathrm{c}$ is useful as such data are correlated to the compressive strength of a variety of cement pastes, mortars and concretes cured across a range of conditions [32].

\subsection{Comments on creep and shrinkage}

The sorption data shown herein quantifiably explains why shrinkage shows an irreversible component upon $\left(1^{\text {st }}\right)$ drying. Specifically, microstructural change that occurs upon first drying, results in rearrangements, which once made, cannot be reversed. These rearrangements are a cause of irreversible volume change, though fissure formation may also play a (smaller) role. Significantly, creep is affected by water content as it has been observed to diminish to very low values when the $\mathrm{RH} \leq 50 \%$ [67-70] indicating that water in the larger gel pores is a necessary part of the irreversible viscous flow [71-76]. Apparently this water is important to viscous flow both during drying and under load. This may suggest rather than the interlayer water, the lubricating effects of water between the globules [77], and any dissolution-precipitation processes therein may be a source of creep in cementing materials [78].

The results reported in this paper can also be cast into the discussion about the nanostructure of $\mathrm{C}-\mathrm{S}-\mathrm{H}$, and mechanisms for shrinkage: (a) where interlayer spaces, rather than the pores control the volumetric response upon drying $[22,79]$ or (b) the nanostructure is granular (particle-like) and its shrinkage is controlled by pores and by contacts between particles [33]. This work highlights that both viewpoints, often thought opposing are valuable. For example, the sorption isotherms shown herein indicate that pores (capillary, and gel, see also Fig. 6c) are certainly important. They dominate the drying response until $\approx 25 \% \mathrm{RH}$. Below this $\mathrm{RH}$, and during adsorption if the paste has been dried to $\leq 25 \% \mathrm{RH}$, the interlayer spaces, and the removal/ re-entry of water from these spaces controls drying/wetting, and consequently the volume change behavior. It is also clear, that while the C-S$\mathrm{H}$ does undergo densification with time, the removal of water from the interlayer spaces, which cannot be resaturated (i.e., at least over reasonable time intervals) is a significant component of irreversible volume change that is noted in cementitious systems. However, for such irreversible volume changes to achieve significant proportions, drying to $\leq 25 \%$ RH is necessary - as was demonstrated by Helmuth $[26,80]$. As such, based on our data, it appears as though the capillary and gel pores control material behavior in typical engineering practice, while the interlayer spaces control the material response, under conditions of exposure to: (a) elevated temperature, and/or (b) pressure.

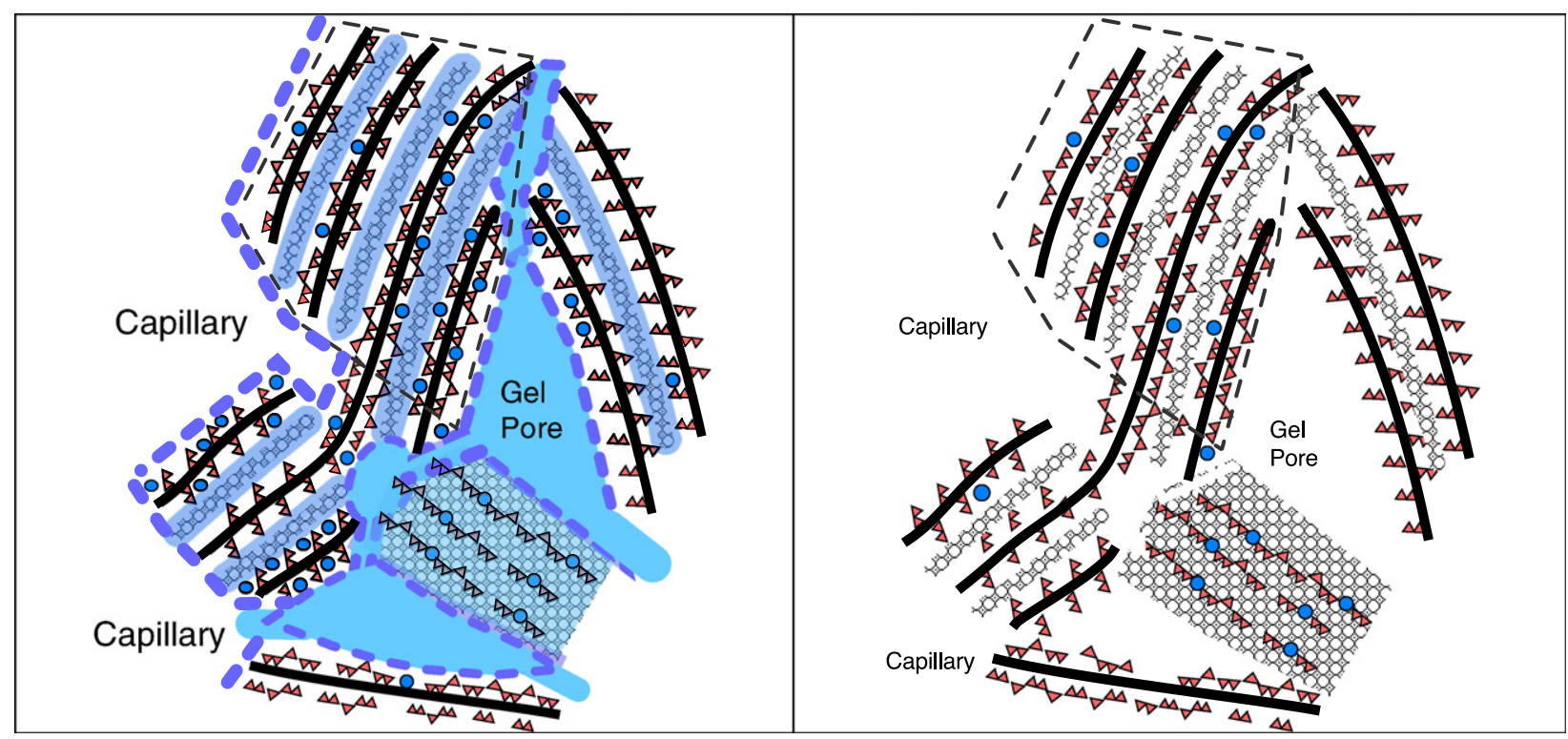

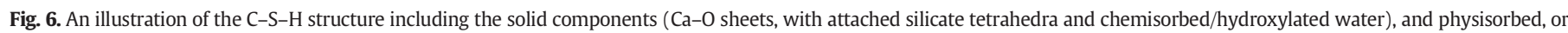
liquid water held in the gel, and capillary pores, respectively. 


\section{Summary and conclusions}

The water isotherm contains significant information of the nano/ microstructure of the $\mathrm{C}-\mathrm{S}-\mathrm{H}$ and cementitious materials in general. Proper capture of sorption isotherms, to differing RH minima can be used to quantitatively explain changes in the pore structure that occur during drying. For example, water that is either being removed or reentering a sample at a particular $\mathrm{RH}$ can be linked quantitatively to a specific class of pores, i.e., the interlayer, gel or capillary spaces. It is noted that capillary pores do not alter up on drying and they likely have little, if any, effect on irreversible volume changes upon drying. On the other hand, gel pores exhibit significant changes up on drying, and aging, and the water isotherm is an ideal measure of these changes. These changes are expected to be related to irreversible volume changes on drying. The removal of water from the interlayer spaces also contributes to irreversible volume changes, especially so up on severe drying, when water previously removed cannot re-enter the interlayer spaces up on resaturation. Because this water is essentially static, unless drying occurs for $\mathrm{RH} \leq 25 \%$, this water (i.e., contained in the interlayer) may be considered constant for engineering purposes.

A new technique is proposed for determining the original $\mathrm{w} / \mathrm{c}$ of any cement-based material in general. The powerful concept of the gel/space ratio is invoked, which allows both capillary and gel volumes to be determined, in relation to the degree of cement reaction, which needs to be separately determined. The proposed method is superior to all existing methods, because there is no need for calibration. This allows use of the method to study concrete, when it deteriorated and for other diagnostic, design and forensic applications. Based on the collective observations, and insights gained herein, this work advances a unified view of $\mathrm{C}-\mathrm{S}-\mathrm{H}$, and potential mechanisms of volume changes therein. It is proposed that gel and capillary pores broadly control properties of engineering relevance, with the inter-layer spaces assuming relevance, only under conditions of elevated temperature and pressure. The discussion provokes new pathways to model, and to better quantify the engineering responses of $\mathrm{C}-\mathrm{S}-\mathrm{H}$, and cementitious materials, in general.

\section{Acknowledgments}

The authors acknowledge full financial support for this research provisioned by the University of California, Los Angeles (UCLA) and National Science Foundation (CAREER Award \#: 1253269, and CMMI: 1066583). The contents of this paper reflect the views and opinions of the authors, who are responsible for the accuracy of datasets presented herein. This research was conducted in the Laboratory for the Chemistry of Construction Materials $\left(\mathrm{LC}^{2}\right)$ and the core-facility Molecular Instrumentation Center (MIC) at the University of California, Los Angeles (UCLA). As such, the authors acknowledge the support that has made these laboratories and their operations possible. The last author would also like to acknowledge discretionary support for this research provided by the Edward K. and Linda L. Rice Endowed Chair in Materials Science. GNS would like to thank Dale Bentz (NIST) for providing him with Richard Helmuth's M.S. thesis at the time of a scientific visit in 2007, and J. J. Beaudoin (NRC) and R. Alizadeh (Giatec Scientific) for discussions on the structure of $\mathrm{C}-\mathrm{S}-\mathrm{H}$, and its water sorption isotherms. Jacob Israelachvili (UCSB) is thanked for his critical insights regarding the structure of clays, the response of layered materials to sorption and desorption processes, and of disjoining pressure.

\section{References}

[1] V. Baroghel-Bouny, Water vapour sorption experiments on hardened cementitious materials: part I: essential tool for analysis of hygral behaviour and its relation to pore structure, Cem. Concr. Res. 37 (3) (2007) 414-437.

[2] S. Brunauer, P.H. Emmett, E. Teller, Adsorption of gases in multimolecular layers, J. Am. Chem. Soc. 60 (2) (1938) 309-319.
[3] S. Brunauer, J. Skalny, E.E. Bodor, Adsorption on nonporous solids, J. Colloid Interface Sci. 30 (4) (1969) 546-552.

[4] S. Brunauer, Physical adsorption. Vol. I of the adsorption of gases and vapors, Princeton Univ. Press, 1943. 7-11.

[5] R.S. Bradley, Polymolecular adsorbed films. Part I. The adsorption of argon on salt crystals at low temperatures, and the determination of surface fields, J. Chem. Soc. 318 (1936) 1467-1474 (Resumed).

[6] J. Hagymassy Jr., S. Brunauer, R.S. Mikhail, Pore structure analysis by water vapor adsorption: I. t-curves for water vapor, J. Colloid Interface Sci. 29 (3) (1969) 485-491.

[7] T.C. Powers, Structure and physical properties of hardened Portland cement paste, J. Am. Ceram. Soc. 41 (1) (1958) 1-6.

[8] I. Odler, J. Hagymassy Jr., M. Yudenfreund, K.M. Hanna, S. Brunauer, Pore structure analysis by water vapor adsorption. IV. Analysis of hydrated Portland cement pastes of low porosity, J. Colloid Interface Sci. 38 (1) (1972) 265-276.

[9] V. Baroghel-Bouny, Water vapour sorption experiments on hardened cementitious materials. Part II: essential tool for assessment of transport properties and for durability prediction, Cem. Concr. Res. 37 (3) (2007) 438-454.

[10] N. De Belie, J. Kratky, S. Van Vlierberghe, Influence of pozzolans and slag on the microstructure of partially carbonated cement paste by means of water vapour and nitrogen sorption experiments and BET calculations, Cem. Concr. Res. 40 (12) (2010) 1723-1733.

[11] J.J. Thomas, H.M. Jennings, A.J. Allen, The surface area of hardened cement paste as measured by various techniques, Concr. Sci. Eng. 1 (1999) 45-64.

[12] Z.P. Bazant, M.Z. Bazant, Theory of Sorption Hysteresis in Nanoporous Solids: I. Snap-through Instabilities, arXiv, 2011. (preprint arXiv:1108.4949).

[13] M.Z. Bazant, Z.P. Bažant, Theory of sorption hysteresis in nanoporous solids: II. Molecular condensation, J. Mech. Phys. Solids 60 (9) (2012) 1660-1675.

[14] J.H. Young, G.L. Nelson, Theory of hysteresis between sorption and desorption isotherms in biological materials, Trans. Am. Soc. Agric. Eng. 10 (1967) 260-263.

[15] J.F. Daian, Condensation and isothermal water transfer in cement mortar. Part I-pore size distribution, equilibrium water condensation and imbibition, Transp. Porous Media 3 (6) (1988) 563-589.

[16] J.F. Daian, Condensation and isothermal water transfer in cement mortar: Part II - transient condensation of water vapor, Transp. Porous Media 4 (1) (1989) $1-16$.

[17] J.H. Young, G.L. Nelson, Research of hysteresis between sorption and desorption isotherms of wheat, Trans. ASAE 10 (6) (1967) 756-761.

[18] R.F. Feldman, P.J. Sereda, A model for hydrated Portland cement paste as deduced from sorption-length change and mechanical properties, Mater. Constr. 1 (6) (1968) 509-520.

[19] M.B. Pinson, H.M. Jennings, M.Z. Bazant, Inferring Pore Size and Network Structure from Sorption Hysteresis, arXiv, 2014. (preprint arXiv:1402.3377).

[20] H.M. Jennings, E. Masoero, M.B. Pinson, E.G. Strekalova, P.A. Bonnaud, H. Manzano, K.J. Van Vliet, Water isotherms, shrinkage and creep of cement paste: hypotheses, models and experiments, Mechanics and Physics of Creep, Shrinkage, and Durability of Concrete: A Tribute to Zdenek P. Bažant, Proceedings of the Ninth International Conference on Creep, Shrinkage, and Durability Mechanics.CONCREEP-9, Cambridge, Massachusetts September, 2013, p. 134.

[21] T.C. Powers, The non-evaporable water content of hardened portland-cement paste-its significance for concrete research and its methods of determination, Portland Cem. Assoc. Bull. 29 (1949) 17.

[22] R.F. Feldman, P.J. Sereda, Sorption of water on compacts of bottle-hydrated cement. II. Thermodynamic considerations and theory of volume change, J. Appl. Chem. 14 (2) (1964) 93-104.

[23] H. Roper, Dimensional change and water sorption studies of cement paste, Highw. Res. Board Spec. Rep. 90 (1966) (Link: http://trid.trb.org/view.aspx?id=101494).

[24] C.L. Hwang, J.F. Young, Drying shrinkage of portland cement pastes I. Microcracking during drying, Cem. Concr. Res. 14 (4) (1984) 585-594

[25] R.A. Helmuth, D.H. Turk, The Reversible and Irreversible Drying Shrinkage of Hardened Portland Cement and Tricalcium Silicate Pastes (215), http://trid.trb.org/view. aspx?id=102162.

[26] R.A. Helmuth, Dimensional changes of hardened Portland cement pastes caused by temperature changes, Highway Res. Board Proc. 40 (1961).

[27] D.P. Bentz, E.J. Garboczi, D.A. Quenard, Modelling drying shrinkage in reconstructed porous materials: application to porous Vycor glass, Model. Simul. Mater. Sci. Eng. 6 (3) (1998) 211.

[28] E.C. Ormerod, A.C.D. Newman, Water sorption on Ca-saturated clays: II. Internal and external surfaces of montmorillonite, Clay Miner. 18 (3) (1983) 289-299.

[29] H.M. Jennings, J.W. Bullard, J.J. Thomas, J.E. Andrade, J.J. Chen, G.W. Scherer, Characterization and modeling of pores and surfaces in cement paste: correlations to processing and properties, J. Adv. Concr. Technol. 6 (1) (2008) 5-29.

[30] P.A. Bonnaud, B. Coasne, R.J. Pellenq, Molecular simulation of water confined in nanoporous silica, J. Phys. Condens. Matter 22 (28) (2010) 284110.

[31] A.C. Muller, K.L. Scrivener, A.M. Gajewicz, P.J. McDonald, Densification of C-S-H measured by ${ }^{1}$ H NMR relaxometry, J. Phys. Chem. C 117 (1) (2012) 403-412.

[32] S. Mindess, J.F. Young, D. Darwin, Concrete, Prentice Hall, 2003.

[33] A.J. Allen, J.J. Thomas, H.M. Jennings, Composition and density of nanoscale calciumsilicate-hydrate in cement, Nat. Mater. 6 (4) (2007) 311-316.

[34] T.C. Powers, Properties of cement paste and concrete, Chemistry of Cement: Fourth International Symposium, 1960.

[35] J.J. Thomas, H.M. Jennings, Effect of heat treatment on the pore structure and drying shrinkage behavior of hydrated cement paste, J. Am. Ceram. Soc. 85 (9) (2002) 2293-2298.

[36] J. Adolphs, A. Schreiber, Microstructural characterization of ultra-high performance concrete, in: M. Schmidt, E. Fehling, C. Geisenhanslüke (Eds.), Proceedings 
International Symposium on Ultra High Performance Concrete, Kassel, Germany 2004, pp. 265-272.

[37] K. Rübner, C. Prinz, J. Adolphs, S. Hempel, A. Schnell, Microstructural characterisation of lightweight granules made from masonry rubble, Microporous Mesoporous Mater. (2014)http://dx.doi.org/10.1016/j.micromeso.2014.08.060.

[38] G.R. Consolazio, M.C. McVay, J.W. Rish III, Measurement and prediction of pore pressures in saturated cement mortar subjected to radiant heating, ACI Mater. J. 95 (5) (1998).

[39] D.N. Winslow, S. Diamond, Specific surface of hardened portland cement paste as determined by small-angle X-ray scattering, J. Am. Ceram. Soc. 57 (5) (1974) 193-197.

[40] R.F. Feldman, P.J. Sereda, A new model for hydrated Portland cement and its practical implications, Eng. J. 53 (8-9) (1970) 53-59.

[41] H. Jennings, M: colloid model of $\mathrm{C}-\mathrm{S}-\mathrm{H}$ and implications to the problem of creep and shrinkage, Mater. Struct. 37 (1) (2004) 59-70.

[42] E.J. Garboczi, J.W. Bullard, Shape analysis of a reference cement, Cem. Concr. Res. 34 (2004) 1933-1937.

[43] M.J. Setzer, C. Duckheim, A. Liebrecht, J. Kruschwitz, The solid-liquid gel-system of hardened cement paste, in: T. Tanabe, K. Sakata, H. Mihashi, R. Sato, K. Maekawa, H. Nakamura (Eds.), Proceedings of CONCREEP-8, Ise-Shima, Japan 2008, pp. 237-243.

[44] A. Kumar, S. Ketel, K. Vance, T. Oey, N. Neithalath, G. Sant, Water vapor sorption in cementitious materials-measurement, modeling and interpretation, Transp. Porous Media 103 (1) (2014) 69-98.

[45] J.J. Beaudoin, L. Raki, R. Alizadeh, ${ }^{29} \mathrm{Si}$ MAS NMR study of the calcium silicate hydrate nanocomposites, Cem. Concr. Compos. 31 (2009) 585-590.

[46] H.M. Jennings, Refinements to colloid model of CSH in cement: CM-II, Cem. Concr. Res. 38 (3) (2008) 275-289.

[47] L.R. Fisher, J.N. Israelachvili, Experimental studies on the applicability of the Kelvin equation to highly curved concave menisci, J. Colloid Interface Sci. 80 (2) (1981) 528-541.

[48] L.R. Fisher, J.N. Israelachvili, Direct measurement of the effect of meniscus forces on adhesion: a study of the applicability of macroscopic thermodynamics to microscopic liquid interfaces, Colloids Surf. 3 (4) (1981) 303-319.

[49] J.J. Beaudoin, B.T. Tamtsia, Effect of drying methods on microstructural changes in hardened cement paste: an AC impedance spectroscopy evaluation, J. Adv. Concr. Technol. 2 (1) (2004) 113-120.

[50] B.T. Tamtsia, J.J. Beaudoin, Effect of solvent exchange on length change and creep of D-dried hydrated $C_{3} S$ paste, Adv. Cem. Res. 13 (1) (2001) 1-9.

[51] C.M. Neubauer, H.M. Jennings, The role of the environmental scanning electron microscope in the investigation of cement-based materials, Scanning 18 (7) (1996) 515-521.

[52] C.M. Neubauer, H.M. Jennings, The use of digital images to determine deformation throughout a microstructure: application to cement paste, J. Mater. Sci. 35 (22) (2000) 5751-5765.

[53] J. Chappuis, A new model for a better understanding of the cohesion of hardened hydraulic materials, Colloids Surf. A Physicochem. Eng. Asp. 156 (1-3) (1999) 223-241.

[54] J. Adolphs, P. Heine, M.J. Setzer, Changes in pore structure and mercury contact angle of hardened cement paste depending on relative humidity, Mater. Struct. 35 (2002) 477-486.

[55] J.J. Völkl, R.E. Beddoe, M.J. Setzer, The specific surface of hardened cement paste by small-angle X-ray scattering effect of moisture content and chlorides, Cem. Concr. Res. 17 (1) (1987) 81-88.
[56] T. Yang, B. Keller, E. Magyari, AFM investigation of cement paste in humid air at different relative humidities, J. Phys. D. Appl. Phys. 35 (2002) L25-L28.

[57] I.G. Richardson, The nature of CSH in hardened cements, Cem. Concr. Res. 29 (8) (1999) 1131-1147.

[58] J.J. Liu, M.S. Khan, Comparison of known and determined water-cement ratios using petrography, ACI Spec. Publ. 191 (1999).

[59] U.H. Jakobsen, P. Laugesen, N. Thaulow, Determination of water-cement ratio in hardened concrete by optical fluorescence microscopy, ACI Spec. Publ. 191 (1999).

[60] S. Sahu, S. Badger, N. Thaulow, R.J. Lee, Determination of water-cement ratio of hardened concrete by scanning electron microscopy, Cem. Concr. Compos. 26 (8) (2004) 987-992.

[61] H.S. Wong, N.R. Buenfeld, Determining the water-cement ratio, cement content, water content and degree of hydration of hardened cement paste: method development and validation on paste samples, Cem. Concr. Res. 39 (10) (2009) 957-965.

[62] T.C. Powers, T.L. Brownyard, Studies of the physical properties of hardened Portland cement paste (nine parts), J. Am. Concr. Inst. 43 (1948) ((Oct. 1946-April 1947), Bulletin 22, Research Laboratories of the Portland Cement Association, Chicago).

[63] L.R. Fisher, J.N. Israelachvili, Direct experimental verification of the kelvin equation for capillary condensation, Nature 277 (1979) (1979) 548.

[64] L.R. Fisher, J.N. Israelachvili, Determination of the capillary pressure in menisci of molecular dimensions, Chem. Phys. Lett. 76 (2) (1980) 325-328.

[65] C. Hall, W.D. Hoff, Water Transport in Brick, Stone and Concrete, Taylor and Francis, 2009.

[66] H.F. Taylor, Cement Chemistry, Thomas Telford, 1997.

[67] Z.P. Bazant, J.C. Chern, Concrete creep at variable humidity: constitutive law and mechanism, Mater. Struct. 18 (1) (1985) 1-20.

[68] R. L'Hermite, Mathematical Modeling of Creep and Shrinkage of Concrete, in: Z.P. Bazant (Ed.) Wiley, New York, 1988.

[69] F.H. Wittmann, Interaction of hardened cement paste and water, J. Am. Ceram. Soc. 56 (8) (1973) 409-415.

[70] F.J. Ulm, Z.P. Bazant, F.H. Wittman, Creep, Shrinkage, and Durability Mechanics of Concrete and Other Quasi-brittle Materials, Elsevier, 2001.

[71] Z.P. Bazant, L. Robert, Mathematical Modeling of Creep and Shrinkage of Concrete, John Wiley and Sons Ltd, Chichester, 1988.

[72] J. Weiss, P. Lura, F. Rajabipour, G. Sant, Performance of shrinkage-reducing admixtures at different humidities and at early ages, ACI Mater. J. 105 (5) (2008) 478.

[73] RILEM Recommendation, Creep and shrinkage prediction model for analysis and design of concrete structures-model B3, Mater. Struct. 28 (357-365) (1995).

[74] F. Benboudjema, F. Meftah, J.M. Torrenti, Interaction between drying, shrinkage, creep and cracking phenomena in concrete, Eng. Struct. 27 (2) (2005) 239-250.

[75] Z.P. Bazant, S.T. Wu, Creep and shrinkage law for concrete at variable humidity, J .Eng. Mech. Div. 100 (6) (1974) 1183-1209.

[76] Z.P. Bažant, Prediction of concrete creep and shrinkage: past, present and future, Nucl. Eng. Des. 203 (1) (2001) 27-38.

[77] I. Vlahinić, H.M. Jennings, J.J. Thomas, A constitutive model for drying of a partially saturated porous material, Mech. Mater. 41 (3) (2009) 319-328.

[78] E.A. Pachon-Rodriguez, E. Guillon, G. Houvenaghel, J. Colombani, Wet creep of hardened hydraulic cements-example of gypsum plaster and implication for hydrated Portland cement, Cem. Concr. Res. 63 (2014) 67-74.

[79] W. Hansen, Drying shrinkage mechanisms in Portland cement paste, J. Am. Ceram. Soc. 70 (5) (1987) 323-328.

[80] R.A. Helmuth, Dimensional Changes and Water Sorption of Hydrated Tricalcium Silicate(M.S. Thesis) Illinois Institute of Technology, 1965. 68 